\title{
Interdisciplinary Education for Physician's Confidentiality by Interdisciplinary Collaboration of Medical and Law Researchers
}

\author{
Ryoju HAMADA ${ }^{1, *}$, Junichi KAMEOKA ${ }^{2}$, Yoshinari KANAYA ${ }^{3}$ and Yutaka KAGAYA ${ }^{4}$ \\ ${ }^{1}$ Sirindhorn International Institute of Technology, Thammasat University, Pathumthani 12000, Thailand \\ ${ }^{2}$ Faculty of Medicine, Tohoku Medical and Pharmaceutical University, Sendai 981-8558, Japan \\ ${ }^{3}$ Faculty of Law, Tohoku University, Sendai 980-8577, Japan \\ ${ }^{4}$ Office of Medical Education, Tohoku University Graduate School of Medicine, Sendai 980-8575, Japan
}

\begin{abstract}
Confidentiality is a fundamental duty of a physician to maintain a safe medical system. The authors are law researchers and medical researchers. We planned interdisciplinary workshops including both legal and medical viewpoints. Encouraging medical students to understand the importance of confidentiality and its exceptions, we studied others' academic fields together over eight years, and established a fixed style of scenario-based group discussions. As a unique characteristic of this project, it includes actual students of law and other fields as facilitators to encourage mobility and circulation among disciplines. The workshop has continued since 2009, once a year. Results of student evaluations show their enhanced understanding of confidentiality as a core value of safety and sustainable medical systems. Other teaching purposes have mostly succeeded. Facilitators regard this workshop as a good opportunity to explore interdisciplinary studies as well. That interest maintains and reinforces the close relationship between these disciplines of study. Therefore, the authors conclude that this innovative workshop is very effective.
\end{abstract}

KEYWORDS: physician, confidentiality, law, facilitator, interdisciplinary education

\section{Introduction}

\subsection{What is a Medical Doctor's Confidentiality?}

Hippocrates practiced as a physician worked in Greece in the fourth century B.C. He is famous as an originator of western medicine as a discipline. His spirit is still respected as the Hippocratic Oath, and is taught by most medical schools worldwide. It includes nine promises to the gods. The ninth promise is confidentiality:

"Whatever, in connection with my professional practice or not, in connection with it, I see or hear, in the life of men, which ought not to be spoken of abroad, I will not divulge, as reckoning that all such should be kept secret."

Nowadays, confidentiality is not merely an ethical requirement: it is a legal duty of physicians. For example, we point out some legal duties of physicians in Japanese laws as shown in Table 1.

Table 1. Major duty of physicians in Japanese laws.

\begin{tabular}{|l|l|l|}
\hline Duty & Legal grounds & Penalty \\
\hline Duty of Medical Treatment on demand & Medical Practitioners' Act Ar.19 (1) & None \\
\hline Duty of providing document on demand & Medical Practitioners' Act Ar.19 (2) & None \\
\hline Duty of Recording medical treatment & Medical Practitioners' Act Ar.24 (1) & Fine up to 500,000 JPY \\
\hline Unlawful Disclosure of Confidential Information & Penal Code Ar. 134 & $\begin{array}{l}\text { Imprisonment and labor less than } 6 \\
\text { months, or Fine up to 100,000 JPY }\end{array}$ \\
\hline
\end{tabular}

Confidentiality is listed in the Penal code, one of the highest laws, its penalty is much higher than those for other duties. The Article is the following:

Received May 8, 2017; Accepted October 17, 2017; J-STAGE Advance published November 10, 2017

${ }^{*}$ Corresponding author. E-mail: hamada@ @iit.tu.ac.th 
(Unlawful Disclosure of Confidential Information)

Article 134 When a physician, pharmacist, pharmaceuticals distributor, midwife, attorney, defense counsel, notary public or any other person formerly engaged in such profession disclose, without justifiable grounds, another person's confidential information which has come to be known in the course of such profession, imprisonment with work for not more than 6 months or a fine of not more than 100,000 yen shall be imposed.

Why is such an article included in the penal code? Among Japanese penal code scholars, it is a common understanding that this clause is to protect patient's personal benefit. However, we consider that this duty is fundamentally important to keep the quality of medicine. If a physician does not protect a patient's information, a patient will refrain from disclosing personal information honestly. In such cases, confidence in the national medication system might be broken.

\subsection{Status of Confidentiality in Japanese Medical School}

In recent days, there is no hospital staff member who does not know the word "Confidentiality" at all. However, they tend to neglect this rule. Confidentiality is a common duty not only for physicians, but nurses, midwives, and public health nurses must refrain from disclosing patients' information as physicians by other laws as well, but the situations are similar. Students of schools of medicine are not yet physicians. Therefore, there is no legislation of confidentiality for them.

In 2002, the Ministry of Education, Culture, Sports, Science and Technology (MEXT) started to standardize medical education and published the guideline commonly called "Model Core Curriculum (MCC)." All schools of medicine in Japan must follow this guideline. Table 2 presents contents of MEXT Model Core Curriculum and points out the reference to ethical/legal duty.

Table 2. Reference to ethical/legal duty of physicians in MCC (2011).

\begin{tabular}{|c|c|c|}
\hline Chapter & $\begin{array}{l}\text { Number } \\
\text { of pages }\end{array}$ & Acknowledgement to Ethical/Legal matters \\
\hline Competencies as a physician & 1 & $\begin{array}{l}\text { (2) To keep the secrets of patients and their family to comply } \\
\text { with the duty of a physician and medical ethics }\end{array}$ \\
\hline A. Fundamentals & 4 & $\begin{array}{l}1 \text { (2) Right of Patients } \\
3 \text { (2) 6) Paying attention to patients' privacy }\end{array}$ \\
\hline B. Medical science, medical care and Society & 2 & $\begin{array}{l}\text { (5) Medical Practitioners' Act } \\
\text { (7) Management of medical information }\end{array}$ \\
\hline C. General Medical Science & 9 & None \\
\hline $\begin{array}{l}\text { D. Structure, function, pathophysiology, diagnosis } \\
\text { and treatment of human organs }\end{array}$ & 21 & None \\
\hline $\begin{array}{l}\text { E. General physiological changes, the diagnosis } \\
\text { of pathophysiology and treatment }\end{array}$ & 6 & None \\
\hline F. Fundamentals of diagnosis and treatment & 9 & None \\
\hline G. Clinical Training & 6 & $\begin{array}{l}1 \text { Acquiring and recording patient's information } \\
2 \text { (3) Be able to devote attention to pain, shame, and privacy } \\
\text { (4) Greeting to patients, dress code, etc. }\end{array}$ \\
\hline
\end{tabular}

Most descriptions of MCC are medical science itself. There is little mention of physicians' duties to patients or society. Actually, MCC does not mention that violation of confidentiality is crime with punishment but explains "be able to devote attention to privacy." Another characteristic is that confidentiality is treated as other benefits of patients; like privacy, shame, attitude toward patient. Therefore, we consider that MCC lacks legal discipline.

\subsection{Literature Review}

Medical education is approved as a diverse research field of medical science. We attend conferences of such academic society as a regular member, and most of them have journals. However, we have never met a presentation or an article that treats confidentiality as a main topic.

As discussed in 1.2, Ethics, Legal duty, and Privacy is comingled in medical education. Akabayashi edited a textbook called "Introduction to Medical Ethics," which is separated in three books. His book is commonly used in many schools of medicine in Japan. This literature has more than 1,000 pages. There are 19 pages chapter called "Confidentiality and Privacy Protection" (Vol. 1, pp. 171-190) [1]. They summarize that confidentiality has an origin in the Hippocratic Oath, and gradually changed its style from "absolute duty" to "soft duty." They explain when either of following conditions is satisfied, confidentiality might be cancelled in that case. 
1) Patient consent

2) In case 1) is impossible to acquire, as

a) Cancellation to protect public order

b) Cancellation to protect third party benefits

c) Cancellation to protect the patient

In terms of medical ethics worldwide, Beauchamp and Childress [2] established a framework to analyze medical ethics. They proposed four principles (Respect for autonomy, Beneficence, Non-maleficence and Justice) that have been respected as a standard and which have been updated for current learners. Hope [3] summarized privacy issue in relation with advanced genetics research (pp. 86-98). Jonsen [4] is also famous for literature particularly addressing clinical treatment. Its eighth edition is available in 2015. Rogers and Draper [5] pointed out in medical ethics research and teaching, cases including sensitive information are often used without consent of patients, most medical journals have no guideline for how to treat such problems, and also mention duties of students to maintain confidentiality. To categorize exceptions of duty of confidence, Blightman, Griffiths, and Danbury [6] proposed there are legally justified exceptions of three types (patient consent, judicial proceedings, and public interest). Agyapong, Kirrane, and Bangaru [7] explain four exceptions, which are judicial proceedings, protection of the patient, public interest, and protection of third parties. Odunsi [8] discusses when sex partner patient has infected with HIV, how doctors should act between duty of confidence, including conflict of privacy and public interest. He explains that in such cases, there is no absolute answer (p. 304). In medical ethics education, scenario-based case studies are commonly used. As an example, we can point out law [9]. He discusses confidentiality and presents three examples in his book (Chapter 5).

\subsection{Confidentiality Workshop by Interdisciplinary Team}

Kameoka (author) has worked for Office of Medical Education (OME) since 2009. He proposed the opening of a new workshop specifically addressing confidentiality, setting the main discipline in law. However, Kameoka is a physician who lacks legal knowledge to manage the workshop. He decided to ask a support to teachers of law. Hamada (author) was a lecturer of law serving for the Graduate School of Information Sciences, mainly teaching undergraduate students. Kameoka sent an invitation letter to Hamada to ask about interdisciplinary education. Hamada welcomed the proposal, visited OME, and started a discussion to launch interdisciplinary teaching. From 2010, Kanaya (author), a lecturer of the law school, has been jointly involved. We repeatedly had discussions and created five scenarios that include medical and legal surfaces. To raise educational effectiveness, we decided to hire student facilitators from other schools. Using this method, we hosted the first "Confidentiality Workshop" in September 2009. The workshop has continued for eight years, including PDCA cycle to improve operation, student satisfaction and accuracy of scenarios. This is a new approach to teach confidentiality based on legal logic, and also a rare trial as a practice of interdisciplinary education.

\section{Methodology}

\subsection{Responsible Organization}

Tohoku University School of Medicine was established in 1915. It has 1,402 students (one of the largest medical schools in Japan), 327 faculty members, and 49 administrative staff (2016, aside from the university hospital). Following MCC Sec. 7, clinical training is required for all students. At the School of Medicine, the Office of Medical Education (OME) is in charge of planning, doing, checking, and action on clinical training. OME is operated by four faculty members and four staff members. They manage clinical training that starts from "Introduction of Medical Science and Medical Care" for first-year students, and ends on "Clinical Elective" for sixth year students. "Introduction of Medical Science and Medical Care" consists of a variety of experiences such as visiting a hospital, medical-interview training, observation of surgical operation, etc. The confidentiality workshop is one part of the various programs.

\subsection{Status and Order of Confidentiality Workshop}

We considered the confidentiality workshop was suitable for a part of "Introduction of Medical Science and Medical Care". Since we believed that confidentiality was one of the most important competencies that medical students should acquire at the beginning of a total of 6-year undergraduate medical education, confidentiality workshops were assigned in the early sessions. At the beginning, we had a full day session. However, we had to change the length to half day, because of the renovation of the whole curriculums of School of Medicine.

\subsection{Target Audiences}

Since "Introduction of Medical Science and Medical Care" is a compulsory course for all first-year medical students of Tohoku University School of Medicine, all of them attended the Confidentiality workshop. 


\subsection{Learning Purposes}

We chose three basic purposes of Confidentiality workshop as described below.

\subsubsection{To understand confidentiality and its exceptions correctly}

In Japan, we have laws with sanction in the penal code article 134. Physicians must maintain confidentiality of knowledge related to the medical practice. Article 134 has exception on when there is a "justifiable reason." What is the significance of Article 134? What are the exceptional cases? Students must be able to judge matters independently.

\subsubsection{To discuss confidentiality actively based on a scenario}

Students tend to recognize legal story as a "matter in the opposite shore." Instead of doing traditional lecture, we adopted active learning. We let students discuss confidentiality using a scenario and present the product of a group work to understand the legal risk.

\subsubsection{Experiencing interdisciplinary practice}

Students communicate with facilitators who mostly came from school of law, listen to law teacher's lectures, and find out interdisciplinary science is fun and makes their vision wider.

\subsection{Processes before the Workshop}

This workshop was prepared using the following processes.

\subsubsection{Kick-off meeting}

Kameoka hosted the first meeting with Hamada and Kanaya approximately three months before the workshop. While following the learning purposes as described in 2.4 , we attempted to improve the workshop by reviewing that in the previous year. We discussed the schedule, scenarios, number of facilitators required, classroom, and team formation.

\subsubsection{Call for facilitators (two months prior)}

To achieve the third learning purpose (2.4.3, interdisciplinary practice), we invited non-medical students as a facilitator. They were called up in three ways, the students who had experience in the workshops earlier, students who saw the poster of this workshop at the School of Law, and students who took Hamada's lecture of law. Here, 4-15 students applied to the workshop. We devoted no attention to their academic age. We treated them by official teachingassistant hiring programs, and pay wages for them as an honorarium for their professional work.

\subsubsection{Pre-workshop for facilitators (one week prior)}

Facilitators were required to attend the pre-workshop meeting to study the scenarios. It was the absolute duty of facilitators. If the facilitator was not able to attend, we recorded the pre-workshop meeting and send the DVD to them. The length of the textbook for facilitators prepared by Hamada and Kanaya exceeded 40 pages. Throughout this practice session, they understood confidentiality, its exceptions, related laws, and the scenarios that they were scheduled to work with.

\subsection{Process of the Day of the Workshop}

\subsubsection{Answering before questionnaire}

At the beginning of the workshop, all students were invited to a large lecture hall. We spent several minutes letting students answer a questionnaire to assess their preparedness. It consisted of about 10 questions, the format of answers is designed to ascertain their understanding in five-point scale $(5=$ Very Good understanding, $4=$ Good understanding, 3 = Acceptable understanding, 2 = Poor understanding, 1 = Very Poor understanding). We urged students not to spend too much time on consideration, but to check on feelings quickly. The sole purpose of this questionnaire is to grasp the learning effectiveness of the workshop by comparing the questionnaire between before and after the workshop. We explained this fact to students and noted that it would not to be graded.

\subsubsection{Introduction}

Kameoka explained to students that there was a legal duty of "confidentiality," showing Article 134 (1), Japanese Penal code by slide, and let students copy the article to their notebooks. The purpose was to apprise students of its importance. Then, to resolve scenarios to help students understand scenarios which require some medical background, the causes of and treatments for certain disorders were explained.

\subsubsection{Separation of group}

From 2009, when the number of first-year students was around 100, it gradually increased especially after the Great East Japan Earthquake in 2011, and finally exceeded 135. After Kanaya participated in this workshop in 2010, it 
became possible to separate students into two large groups using two lecture halls while students presented their products of group discussion. Hamada and Kanaya served as a main teachers, Kameoka managed whole progress, facilitators took care of students' questions, and OME staff members took care of paper documents, ICT devices, and timekeeping.

\subsubsection{Group discussion}

Individual discussions were generally operated by 8-10 students/16-20 groups. Students in each group were provided with a PC, whiteboard, and partition. After 2015, each group used a small seminar room. This idea was to minimize bias from the group discussing the same topic. All students were strongly encouraged to contribute to the discussion. Table 3 presents an example of roles of students.

Table 3. Duty of students in group discussion (2016).

\begin{tabular}{|l|}
\hline Reading Scenario Orally \\
\hline Chairperson \\
\hline Secretary \\
\hline Summarizing topics on a white board \\
\hline Preparing Power Point ${ }^{\mathrm{TM}}$ for classroom discussion \\
\hline Presentation \\
\hline
\end{tabular}

At this moment, they read their scenario first for the first time. Initially, most students were surprised because of its high abstraction level. Therefore, the solution was diverse. Within a limited time, they had to analyze complex scenarios, talk, write, compromise, and reconfirm. Throughout such processes, they learned that law was not a discipline like mathematics. In doing so, they were able to satisfy their learning purposes two and three (2.4.2 and 3).

\subsubsection{Classroom presentation}

The main teachers organized 10 presentations. In a half-day session, we used six scenarios at once. In a full-day session, we used easy scenarios first, and proceed to difficult scenarios. Discussion of only one side was prohibited. For example, even if group argued "I can disclose the fact," the group had to mention reasons "not to disclose" as well in their presentation. In doing so, we contributed to learning purpose No. 3.

\subsubsection{Debriefing lecture}

OME staff members provided a Power Point ${ }^{\mathrm{TM}}$ handout. The main teachers started a lecture to summarize the scenario from a legal viewpoint. Sometimes, facilitators summarized students' discussion first, and the teachers explained the law related to the scenario. We never criticized students. We encouraged students and delivered a strong message "Do not escape."

\subsubsection{Closing speech}

All students and staff members returned to a large lecture hall. Kameoka provided a core lecture related to confidentiality. His lecture consisted of the following ideas.

1) What is confidentiality?

2) Why do we have to respect confidentiality?

3) What are the justifiable grounds in Article 134(1)?

Confidentiality is a requirement of law, all physicians must follow and respect it. However, this principle has exceptions. The most common exception is gaining the consent of patients. In cases where we cannot gain the consent of the patient, we can consider three possibilities under which confidentiality can be cancelled.

a) As with a tuberculosis patient (Scenario 2), to preserve public health, physician disclosure to public health authority might be necessary.

b) As with a critical depression patient (Scenario 4), to save a patient from suicide risk, physician disclosure to guardians might be necessary, but many students have different idea. To summarize the idea of group, they have to discuss positively.

c) As with a dementia patient who is driving a car (Scenario 6), to prevent accidents, physicians disclose to driver license authorities might be necessary, but it depends on the situation. In order to become a good physician, sometimes they have to learn different discipline like facilitators do.

These ideas are all included or suggested in the six scenarios. Using individual scenarios, Kameoka explained the 
rule, and also logic and rhetoric hidden in each scenario. Finally, Kameoka introduced teachers and facilitators again, disclosed his purpose to invite outside human resources, and encouraged students to communicate with other fields while they were young.

\subsubsection{After questionnaire}

Using the same questions as those given before the workshop, we conducted a post-survey. It was conducted by OME staff members. Results were compared with those obtained before the workshop. Additionally, OME conducted a survey of satisfaction.

\subsubsection{Review meeting by facilitators, teachers, and staff members}

After students went home, all teachers, facilitators, and OME staff members had a meeting to discuss operations while their memory was fresh. We spent about an hour. Kameoka compiled a document to summarize discussion, and distributed to facilitators by e-mail later. This record could be used to prepare work for the next year. Consequently, we followed a Plan, Do, Check, and Action (PDCA) cycle every year.

\subsection{Scenarios}

The most unique intellectual asset developed throughout the eight year history is scenarios. To develop this, Hamada and Kanaya aimed to set the level as the same as the bar exam in Japan. Moreover, Kameoka consulted physicians in specific fields to reserve accuracy in terms of medical science.

\subsubsection{Preparing various scenarios}

We prepare six scenarios every year (See Appendix). Scenarios 1-3 are basic; 4-6 are a bit more complex. Scenario 6 includes ideas that were actually experienced in Japanese society (See Scenario 6-2). Depending on the time (half day or full day), we assigned one or two scenarios to students.

\subsubsection{Logic and rhetoric in scenarios}

Using “Child Abuse Scenario (No. 1)", we explain how to read, interpret, and lead resolution.

\section{Scenario 1 Suspected Child Abuse}

A four-year-old boy who had been injured after falling from a veranda in the middle of the night was transferred to the division of emergency medicine at M Hospital, where you worked as an orthopedic physician. His injury was not severe. You treated the boy successfully. However, you found many marks on his stomach. His 37-year-old father seemed quite normal, and explained that the marks had been caused by sports training. Do you acknowledge his explanation and let the child go home?

Most scenarios were short readings like this. It seems like authors wrote dispassionately, but included deep logic and rhetoric traps. In this scenario, in the middle of the night, why did the child fall down from the veranda? In such abnormal situations, why was the injury so light? What kind of sport makes marks on the stomach? Those facts strongly suggest a possibility of child abuse. However, if so, why did the father take his son to a hospital taking a risk of being reported to the officials? Why he came in during the middle of the night to the division of emergency medicine, despite his behavior itself being very conspicuous?

\subsubsection{Example of solution}

Maybe a reader of this paper can interpret this scenario in two ways. Student A may argue "This is child abuse. Therefore, we can say this is a case of "the justifiable grounds" with an argument in Article 134." Student B may present opposite ideas. They came to treat injuries from falling from the veranda, and the marks have no relation to physician duties. Student C may point out that if we dismiss the boy, he might lose his life. Students will strain against contradictory ideas. Generally speaking, it is impossible to comprehend all aspects of an incident perfectly by a short textual explanation. Facts are described in sentences, and various means of interpretation arise. Students seek the truth as they read between the lines, sentence and sentence, and produce different interpretations. In doing so, they can see lawyer's mode of thinking. In other words, the so-called "legal mind," is cultivated as the third teaching purpose (2.4.3).

\subsection{Facilitators}

Law exists far away from medical students. For Hamada and Kanaya, it is quite easy to explain legal ideas to students in a lecture hall. However, to raise a hand to ask a question to a law teacher is an obstacle for the students. To reduce the distance between law/law teachers and students is the mission of facilitators. From their viewpoints, medical students' ideas seem straight and fresh, stimulate their own ideas, and enlarge their world. From our viewpoints, to provide such opportunity and duty to conduct students in different fields is also important for their growth. Learning confidentiality of a physician does not raise an academic score, but it is interesting and fun. Therefore, some facilitators 
worked for many years. Friendship among facilitators and senior and junior members was fostered. They got a wide viewpoint. We are sure such students will work well in the society.

\subsection{Statistical Analysis}

Comparisons of the frequency of top two positive responses (5 and 4) relative to the others $(3,2$, and 1$)$ between before and after the workshop were made using pooled data from 2009 to 2015 and chi-square test. A $p$-value of $<0.05$ was considered statistically significant.

\section{Results}

\subsection{Demographic Information}

The participants in the Confidentiality Workshop were all first-year medical students of Tohoku University School of Medicine between 2009 and 2016. Table 4 presents the outline.

Table 4. Experience of Confidentiality Workshop.

\begin{tabular}{|l|l|l|l|l|}
\hline Date & Time & Student & Instructors & Facilitator \\
\hline $2009 / 08 / 31$ & $3 \mathrm{~h} 30 \mathrm{~m}$ & 117 & JK, RH, HK & 4 \\
\hline $2010 / 09 / 06$ & $4 \mathrm{~h}$ & 111 & JK, RH, YK, HK & 9 \\
\hline $2011 / 09 / 27$ & $7 \mathrm{~h}$ & 123 & JK, RH, YK, HK & 9 \\
\hline $2012 / 09 / 28$ & $7 \mathrm{~h}$ & 131 & JK, RH, YK, HK & 9 \\
\hline $2013 / 09 / 26$ & $3 \mathrm{~h} 10 \mathrm{~m}$ & 136 & JK, RH, YK, HK & 17 \\
\hline $2014 / 09 / 12$ & $4 \mathrm{~h}$ & 136 & JK, RH, YK & 4 \\
\hline $2015 / 07 / 13$ & 3h $10 \mathrm{~m}$ & 137 & JK, RH, YK, KG & 4 \\
\hline $2016 / 07 / 11$ & 3h $10 \mathrm{~m}$ & 138 & JK, RH, YK, KG & 7 \\
\hline
\end{tabular}

(Teachers' names: $\mathrm{JK}=$ Kameoka, $\mathrm{RH}=$ Hamada, $\mathrm{HK}=$ Hiroshi Kanazuka (Former Faculty Member) $\mathrm{YK}=$ Kanaya, $\mathrm{KG}=$ Kagaya. The workshop took place only in the morning except for 2011 and 2012.)

\subsection{Timetable}

In Table 5, we present the workshop timetable. We had one group discussion of scenarios except for 2011 and 2012. As described in 2.7.1, when we have a full day, we repeat this process using easier scenarios first and difficult scenarios later.

Table 5. Actual time schedule example (2016, $3 \mathrm{~h} 10 \mathrm{~min})$.

\begin{tabular}{|c|c|c|c|}
\hline \multicolumn{2}{|c|}{ Time } & Contents & Person in charge \\
\hline $8: 50$ & $-9: 10$ & Questionnaire before workshop and introduction & $\mathrm{JK}$ \\
\hline $9: 15$ & $-9: 55$ & Individual group discussion on one of 6 scenarios & Facilitators \\
\hline $\begin{array}{l}10: 05 \\
10 \cdot 35\end{array}$ & $\begin{array}{l}-10: 35 \\
-\quad 11 \cdot 00\end{array}$ & $\begin{array}{l}\text { Presentation } 1 \text { ( } 6 \text { groups for } 3 \text { scenarios, } 3 \text { min presentation and } 2 \text { min } \\
\text { Q \& A for each of } 6 \text { groups) }\end{array}$ & \\
\hline $\begin{array}{l}11: 00 \\
11: 20\end{array}$ & $\begin{array}{l}-11: 20 \\
-\quad 11: 35\end{array}$ & $\begin{array}{l}\text { Presentation } 2 \text { ( } 4 \text { groups for } 3 \text { scenarios, } 3 \text { min presentation and } 2 \text { min } \\
\text { Q \& A for each of } 4 \text { groups) } \\
\text { Debriefing for Part } 2\end{array}$ & Question and Answer: facilitators \\
\hline $11: 40$ & $-12: 00$ & $\begin{array}{l}\text { Summary, debrief and closing remarks } \\
\text { Questionnaire after workshop }\end{array}$ & JK \\
\hline
\end{tabular}

\subsection{Course Evaluation}

Did our students really understand our intention? Is our teaching purpose satisfied? We evaluated the results of before/after questionnaires consisting of several five-point scale questions. $(1 \Leftarrow$ strongly do not understandstrongly Understand $\Rightarrow 5$ ). Table 6 presents a list of major questions which are the same in before and after. 
Table 6. List of major questions.

\begin{tabular}{|c|c|}
\hline No. & Question \\
\hline 1 & Physician has confidentiality, disclosing patient secrets is prohibited. \\
\hline 2 & Confidentiality can be canceled in exceptional cases when some requirements are satisfied. \\
\hline 3 & In the elevator, there are many people listening to your story. \\
\hline 4 & There are some circumstances under which a physician is obligated to report the information of patients to officials. \\
\hline 5 & Employees ask the president's condition to prepare for the worst case. In this case, the physician can explain to them. \\
\hline 6 & $\begin{array}{l}\text { Physicians should not use a blog or social network services without careful consideration, no matter how much freedom } \\
\text { of speech is valued. }\end{array}$ \\
\hline
\end{tabular}

\subsection{1 "Confidentiality" is already known by most students}

Even though they had no previous knowledge related to law, most of them knew of the term "Confidentiality". Pooled data from 2011 to 2015 revealed that top two positive responses (5 and 4) increased significantly after the workshop as compared with before by approximately 3.5 points $(\mathrm{p}=0.0026)$ (Table 7).

Table 7. Understanding of "Confidentiality".

\begin{tabular}{|c|c|c|c|c|c|c|}
\hline Year & Status & $\begin{array}{c}\text { Positive } \\
(5,4)\end{array}$ & $\begin{array}{l}\text { Average } \\
\text { (3) }\end{array}$ & $\begin{array}{c}\text { Negative } \\
(1,2)\end{array}$ & N/A & Total \\
\hline \multirow{4}{*}{2011} & \multirow{2}{*}{ Before } & 121 & 1 & 1 & 0 & 123 \\
\hline & & $98.4 \%$ & $0.8 \%$ & $0.8 \%$ & $0.0 \%$ & $100 \%$ \\
\hline & \multirow{2}{*}{ After } & 122 & 0 & 0 & 0 & 122 \\
\hline & & $100.0 \%$ & $0.0 \%$ & $0.0 \%$ & $0.0 \%$ & $100 \%$ \\
\hline \multirow{4}{*}{2012} & \multirow{2}{*}{ Before } & 112 & 8 & 1 & 13 & 134 \\
\hline & & $83.6 \%$ & $6.0 \%$ & $0.8 \%$ & $9.7 \%$ & $100 . \%$ \\
\hline & \multirow{2}{*}{ After } & 123 & 1 & 0 & 9 & 133 \\
\hline & & $92.5 \%$ & $0.8 \%$ & $0.0 \%$ & $6.8 \%$ & $100 \%$ \\
\hline \multirow{4}{*}{2013} & \multirow{2}{*}{ Before } & 113 & 5 & 1 & 9 & 128 \\
\hline & & $88.3 \%$ & $3.9 \%$ & $0.8 \%$ & $7.0 \%$ & $100 \%$ \\
\hline & \multirow{2}{*}{ After } & 124 & 2 & 0 & 10 & 136 \\
\hline & & $91.2 \%$ & $1.5 \%$ & $0.0 \%$ & $7.4 \%$ & $100 \%$ \\
\hline \multirow{4}{*}{2014} & \multirow{2}{*}{ Before } & 132 & 1 & 0 & 4 & 137 \\
\hline & & $96.4 \%$ & $0.7 \%$ & $0.0 \%$ & $2.9 \%$ & $100 \%$ \\
\hline & \multirow{2}{*}{ After } & 132 & 3 & 0 & 1 & 136 \\
\hline & & $97.1 \%$ & $2.2 \%$ & $0.0 \%$ & $0.7 \%$ & $100 \%$ \\
\hline \multirow{4}{*}{2015} & \multirow{2}{*}{ Before } & 132 & 4 & 3 & 0 & 139 \\
\hline & & $95.0 \%$ & $2.9 \%$ & $2.2 \%$ & $0.0 \%$ & $100 \%$ \\
\hline & \multirow{2}{*}{ After } & 130 & 1 & 1 & 0 & 132 \\
\hline & & $98.5 \%$ & $0.8 \%$ & $0.8 \%$ & $0.0 \%$ & $100 \%$ \\
\hline \multirow{5}{*}{ TOTAL } & \multirow{2}{*}{ Before } & 610 & 19 & 6 & 26 & 661 \\
\hline & & $92.3 \%$ & $2.9 \%$ & $0.9 \%$ & $3.9 \%$ & $100 \%$ \\
\hline & \multirow{2}{*}{ After } & 631 & 7 & 1 & 20 & 659 \\
\hline & & $95.8 \%$ & $1.1 \%$ & $0.2 \%$ & $3.0 \%$ & $100 \%$ \\
\hline & $\mathrm{A} / \mathrm{B}$ & $103.4 \%$ & $36.8 \%$ & $16.7 \%$ & $76.9 \%$ & - \\
\hline
\end{tabular}




\subsubsection{Cancellation of confidentiality: Remarkably increased after the workshop}

Against Hippocrates's oath, Japanese penal code Article 134 accepts disclosure of a patient's private information under the "justifiable background." Regarding this topic, as Table 8 shows, we can see students' remarkable growth of understandings. After the workshop, 95.8\% of students from 2011 to 2015 had understood the idea well after the workshop, which was significantly higher than that before the workshop $(\mathrm{p}<0.0001)$. Therefore, we can say that learning purpose No. 1 (2.4.1) was achieved.

Table 8. Understanding of "Exception of Confidentiality".

\begin{tabular}{|c|c|c|c|c|c|c|}
\hline Year & Status & $\begin{array}{l}\text { Positive } \\
(5,4)\end{array}$ & $\begin{array}{c}\text { Average } \\
\text { (3) }\end{array}$ & $\begin{array}{c}\text { Negative } \\
(1,2)\end{array}$ & N/A & Total \\
\hline \multirow{4}{*}{2011} & \multirow{2}{*}{ Before } & 29 & 36 & 58 & 0 & 123 \\
\hline & & $23.6 \%$ & $29.3 \%$ & $47.2 \%$ & $0.0 \%$ & $100 \%$ \\
\hline & \multirow{2}{*}{ After } & 121 & 1 & 0 & 0 & 122 \\
\hline & & $99.2 \%$ & $0.8 \%$ & $0.0 \%$ & $0.0 \%$ & $100 \%$ \\
\hline \multirow{4}{*}{2012} & \multirow{2}{*}{ Before } & 54 & 34 & 33 & 13 & 134 \\
\hline & & $40.3 \%$ & $25.4 \%$ & $24.6 \%$ & $9.7 \%$ & $100 \%$ \\
\hline & \multirow{2}{*}{ After } & 124 & 0 & 0 & 9 & 133 \\
\hline & & $93.2 \%$ & $0.0 \%$ & $0.0 \%$ & $6.8 \%$ & $100 \%$ \\
\hline \multirow{4}{*}{2013} & \multirow{2}{*}{ Before } & 43 & 40 & 46 & 9 & 138 \\
\hline & & $32.0 \%$ & $29.0 \%$ & $33.3 \%$ & $6.5 \%$ & $100 \%$ \\
\hline & \multirow{2}{*}{ After } & 121 & 4 & 0 & 10 & 135 \\
\hline & & $89.6 \%$ & $3.0 \%$ & $0.0 \%$ & $7.4 \%$ & $100 \%$ \\
\hline \multirow{4}{*}{2014} & \multirow{2}{*}{ Before } & 40 & 42 & 51 & 4 & 137 \\
\hline & & $29.2 \%$ & $30.7 \%$ & $37.2 \%$ & $2.9 \%$ & $100 \%$ \\
\hline & \multirow{2}{*}{ After } & 131 & 3 & 1 & 1 & 136 \\
\hline & & $96.3 \%$ & $2.2 \%$ & $0.7 \%$ & $0.7 \%$ & $100 \%$ \\
\hline \multirow{4}{*}{2015} & \multirow{2}{*}{ Before } & 62 & 49 & 26 & 0 & 137 \\
\hline & & $45.3 \%$ & $35.8 \%$ & $19.0 \%$ & $0.0 \%$ & $100 \%$ \\
\hline & \multirow{2}{*}{ After } & 134 & 2 & 0 & 0 & 136 \\
\hline & & $98.5 \%$ & $1.5 \%$ & $0.0 \%$ & $0.0 \%$ & $100 \%$ \\
\hline \multirow{5}{*}{ TOTAL } & \multirow{2}{*}{ Before } & 228 & 201 & 214 & 26 & 669 \\
\hline & & $34.1 \%$ & $30.0 \%$ & $32.0 \%$ & $3.9 \%$ & $100 \%$ \\
\hline & \multirow{2}{*}{ After } & 631 & 10 & 1 & 20 & 662 \\
\hline & & $95.3 \%$ & $1.5 \%$ & $0.2 \%$ & $3.0 \%$ & $100 \%$ \\
\hline & $\mathrm{A} / \mathrm{B}$ & $276.8 \%$ & $5.0 \%$ & $0.5 \%$ & $76.9 \%$ & - \\
\hline
\end{tabular}




\subsubsection{Awareness of risk of information leakage raised}

To share patient information within the closed medical office is not a violation of confidentiality. However, physicians sometimes exchange patient information in public space such as restaurants and trains. An elevator in the hospital is a likely place to meet a friend. To maintain confidentiality, awareness of information related risks should be recognized among physicians. The workshop encouraged students to be more careful about this risk since more students answered that they were well aware of information leakage risk after the workshop than before (83.7 vs $58.3 \%$, $\mathrm{p}<0.0001$, Table 9).

Table 9. Awareness of information leakage risk.

\begin{tabular}{|c|c|c|c|c|c|c|}
\hline Year & Status & $\begin{array}{c}\text { Positive } \\
(5,4)\end{array}$ & $\begin{array}{c}\text { Average } \\
\text { (3) }\end{array}$ & $\begin{array}{c}\text { Negative } \\
(1,2)\end{array}$ & $\mathrm{N} / \mathrm{A}$ & Total \\
\hline \multirow{3}{*}{2011} & Before & $\begin{array}{r}79 \\
64.2 \%\end{array}$ & $\begin{array}{r}26 \\
21.1 \%\end{array}$ & $\begin{array}{r}18 \\
14.6 \%\end{array}$ & $\begin{array}{r}0 \\
0.0 \%\end{array}$ & $\begin{array}{r}123 \\
100 \%\end{array}$ \\
\hline & \multirow{2}{*}{ After } & 113 & 7 & 2 & 0 & 122 \\
\hline & & $92.6 \%$ & $5.7 \%$ & $1.6 \%$ & $0.0 \%$ & $100 \%$ \\
\hline \multirow{4}{*}{2012} & \multirow{2}{*}{ Before } & 72 & 28 & 19 & 13 & 132 \\
\hline & & $54.6 \%$ & $21.2 \%$ & $14.4 \%$ & $9.9 \%$ & $100 \%$ \\
\hline & \multirow{2}{*}{ After } & 108 & 8 & 7 & 9 & 132 \\
\hline & & $81.8 \%$ & $6.1 \%$ & $5.3 \%$ & $6.8 \%$ & $100 \%$ \\
\hline \multirow{4}{*}{2013} & \multirow{2}{*}{ Before } & 72 & 30 & 27 & 9 & 138 \\
\hline & & $52.2 \%$ & $21.7 \%$ & $19.6 \%$ & $6.5 \%$ & $100 \%$ \\
\hline & \multirow{2}{*}{ After } & 100 & 15 & 10 & 11 & 136 \\
\hline & & $73.5 \%$ & $11.0 \%$ & $7.4 \%$ & $8.1 \%$ & $100 \%$ \\
\hline \multirow{4}{*}{2014} & \multirow{2}{*}{ Before } & 77 & 29 & 27 & 4 & 137 \\
\hline & & $56.2 \%$ & $21.2 \%$ & $19.7 \%$ & $2.9 \%$ & $100 \%$ \\
\hline & \multirow{2}{*}{ After } & 109 & 14 & 12 & 1 & 136 \\
\hline & & $80.2 \%$ & $10.3 \%$ & $8.8 \%$ & $0.7 \%$ & $100 \%$ \\
\hline \multirow{4}{*}{2015} & \multirow{2}{*}{ Before } & 89 & 24 & 24 & 0 & 137 \\
\hline & & $65.0 \%$ & $17.5 \%$ & $17.5 \%$ & $0.0 \%$ & $100 \%$ \\
\hline & \multirow{2}{*}{ After } & 124 & 7 & 5 & 0 & 136 \\
\hline & & $91.2 \%$ & $5.2 \%$ & $3.7 \%$ & $0.0 \%$ & $100 \%$ \\
\hline \multirow{5}{*}{ TOTAL } & \multirow{2}{*}{ Before } & 389 & 137 & 115 & 26 & 667 \\
\hline & & $58.3 \%$ & $20.5 \%$ & $17.2 \%$ & $3.9 \%$ & $100 \%$ \\
\hline & \multirow{2}{*}{ After } & 554 & 51 & 36 & 21 & 662 \\
\hline & & $83.7 \%$ & $7.7 \%$ & $5.4 \%$ & $3.2 \%$ & $100.00 \%$ \\
\hline & $\mathrm{A} / \mathrm{B}$ & $142.4 \%$ & $37.2 \%$ & $31.3 \%$ & $80.8 \%$ & - \\
\hline
\end{tabular}




\subsubsection{Understanding of exceptions under Japanese law}

Act on the Prevention of Infectious Diseases and Medical Care for Patients with Infectious Diseases, Child Abuse Prevention Act. Some laws require or permit physicians to notice government authority. These articles declare that following these articles must not be interpreted as a violation of Article 134(1). Our Scenario included those ideas, and summarized in Table 10. Students' understanding had more than doubled after the workshop (89.7 vs 37.6\%, $\mathrm{p}<0.0001)$.

Table 10. Understandings of legal exception.

\begin{tabular}{|c|c|c|c|c|c|c|}
\hline Year & Status & $\begin{array}{c}\text { Positive } \\
(5,4)\end{array}$ & $\begin{array}{c}\text { Average } \\
\text { (3) }\end{array}$ & $\begin{array}{c}\text { Negative } \\
(1,2)\end{array}$ & $\mathrm{N} / \mathrm{A}$ & Total \\
\hline \multirow{4}{*}{2011} & \multirow{2}{*}{ Before } & 41 & 43 & 39 & 0 & 123 \\
\hline & & $33.3 \%$ & $35.0 \%$ & $31.7 \%$ & $0.0 \%$ & $100 \%$ \\
\hline & \multirow{2}{*}{ After } & 112 & 6 & 3 & 0 & 121 \\
\hline & & $92.6 \%$ & $5.0 \%$ & $2.5 \%$ & $0.0 \%$ & $100 \%$ \\
\hline \multirow{4}{*}{2012} & \multirow{2}{*}{ Before } & 34 & 41 & 45 & 13 & 133 \\
\hline & & $25.6 \%$ & $30.8 \%$ & $33.8 \%$ & $9.8 \%$ & $100 \%$ \\
\hline & \multirow{2}{*}{ After } & 111 & 6 & 5 & 9 & 131 \\
\hline & & $84.7 \%$ & $4.6 \%$ & $3.8 \%$ & $6.9 \%$ & $100 \%$ \\
\hline \multirow{4}{*}{2013} & \multirow{2}{*}{ Before } & 59 & 29 & 40 & 9 & 137 \\
\hline & & $43.1 \%$ & $21.2 \%$ & $29.2 \%$ & $6.6 \%$ & $100 \%$ \\
\hline & \multirow{2}{*}{ After } & 114 & 7 & 4 & 11 & 136 \\
\hline & & $83.8 \%$ & $5.2 \%$ & $2.9 \%$ & $8.1 \%$ & $100 \%$ \\
\hline \multirow{4}{*}{2014} & \multirow{2}{*}{ Before } & 55 & 43 & 35 & 4 & 137 \\
\hline & & $40.2 \%$ & $31.4 \%$ & $25.6 \%$ & $2.9 \%$ & $100 \%$ \\
\hline & \multirow{2}{*}{ After } & 124 & 9 & 2 & 1 & 136 \\
\hline & & $91.2 \%$ & $6.6 \%$ & $1.5 \%$ & $0.7 \%$ & $100 \%$ \\
\hline \multirow{4}{*}{2015} & \multirow{2}{*}{ Before } & 62 & 45 & 30 & 0 & 137 \\
\hline & & $45.3 \%$ & $32.9 \%$ & $21.9 \%$ & $0.0 \%$ & $100 \%$ \\
\hline & \multirow{2}{*}{ After } & 131 & 4 & 1 & 0 & 136 \\
\hline & & $96.3 \%$ & $2.9 \%$ & $0.7 \%$ & $0.0 \%$ & $100 \%$ \\
\hline \multirow{5}{*}{ TOTAL } & \multirow{2}{*}{ Before } & 251 & 201 & 189 & 26 & 667 \\
\hline & & $37.6 \%$ & $30.1 \%$ & $28.3 \%$ & $3.9 \%$ & $100 \%$ \\
\hline & \multirow{2}{*}{ After } & 592 & 32 & 15 & 21 & 660 \\
\hline & & $89.7 \%$ & $4.9 \%$ & $2.3 \%$ & $3.2 \%$ & $100.00 \%$ \\
\hline & $\mathrm{A} / \mathrm{B}$ & $235.9 \%$ & $15.9 \%$ & $7.9 \%$ & $80.8 \%$ & - \\
\hline
\end{tabular}




\subsubsection{Different solutions in the same legal issues}

Confidentiality will be canceled if a patient agrees. In cases where a physician cannot obtain consent, then to protect society's, a patient's, or third party's interest will be required as a reason. However, such decisions must be made by a case-by-case basis. Therefore, the resolution should be diverse. Regarding the same problem, more than two answers might be considered. That is the legal mind that we want to encourage in the student. Question is "The employees ask president's condition to prepare for the worst case. In this case, physicians can explain it to them." The answer is presented in Table 11. At the before stage, most students denied disclosure. However, in the after stage, their opinion had been separated, and more students agreed that understanding on legal issues had many aspects (35.6 vs $12.8 \%$, $\mathrm{p}<0.0001)$. This result demonstrates that they understood the nature of legal problems.

Table 11. Understanding on legal issues has many aspects.

\begin{tabular}{|c|c|c|c|c|c|c|}
\hline Year & Status & $\begin{array}{c}\text { Positive } \\
(5,4)\end{array}$ & $\begin{array}{c}\text { Average } \\
\text { (3) }\end{array}$ & $\begin{array}{c}\text { Negative } \\
(1,2)\end{array}$ & N/A & Total \\
\hline \multirow{3}{*}{2011} & Before & $\begin{array}{r}7 \\
57 \%\end{array}$ & $\begin{array}{r}35 \\
28\end{array}$ & $\begin{array}{r}81 \\
659 \%\end{array}$ & $\begin{array}{r}0 \\
0 . \%\end{array}$ & 123 \\
\hline & \multirow{2}{*}{ After } & 50 & 33 & 39 & 0 & 122 \\
\hline & & $41.0 \%$ & $27.1 \%$ & $32.0 \%$ & $0.0 \%$ & $100 \%$ \\
\hline \multirow{4}{*}{2012} & \multirow{2}{*}{ Before } & 14 & 28 & 78 & 13 & 133 \\
\hline & & $10.5 \%$ & $21.1 \%$ & $58.7 \%$ & $9.8 \%$ & $100 \%$ \\
\hline & \multirow{2}{*}{ After } & 44 & 40 & 39 & 9 & 132 \\
\hline & & $33.3 \%$ & $30.3 \%$ & $29.6 \%$ & $6.8 \%$ & $100 \%$ \\
\hline \multirow{4}{*}{2013} & \multirow{2}{*}{ Before } & 27 & 42 & 58 & 9 & 136 \\
\hline & & $19.9 \%$ & $30.9 \%$ & $42.7 \%$ & $6.6 \%$ & $100 \%$ \\
\hline & \multirow{2}{*}{ After } & 40 & 43 & 43 & 11 & 137 \\
\hline & & $29.2 \%$ & $31.4 \%$ & $31.4 \%$ & $8.0 \%$ & $100 \%$ \\
\hline \multirow{4}{*}{2014} & \multirow{2}{*}{ Before } & 15 & 34 & 84 & 4 & 137 \\
\hline & & $11.0 \%$ & $24.8 \%$ & $61.3 \%$ & $2.9 \%$ & $100 \%$ \\
\hline & \multirow{2}{*}{ After } & 43 & 33 & 58 & 2 & 136 \\
\hline & & $31.6 \%$ & $24.3 \%$ & $42.7 \%$ & $1.5 \%$ & $100 \%$ \\
\hline \multirow{4}{*}{2015} & \multirow{2}{*}{ Before } & 22 & 34 & 81 & 0 & 137 \\
\hline & & $16.1 \%$ & $24.8 \%$ & $59.1 \%$ & $0.0 \%$ & $100 \%$ \\
\hline & \multirow{2}{*}{ After } & 59 & 40 & 37 & 0 & 136 \\
\hline & & $43.4 \%$ & $29.4 \%$ & $27.2 \%$ & $0.0 \%$ & $100 \%$ \\
\hline \multirow{5}{*}{ TOTAL } & \multirow{2}{*}{ Before } & 85 & 173 & 382 & 26 & 666 \\
\hline & & $12.8 \%$ & $26.0 \%$ & $57.4 \%$ & $3.9 \%$ & $100 \%$ \\
\hline & \multirow{2}{*}{ After } & 236 & 189 & 216 & 22 & 663 \\
\hline & & $35.60 \%$ & $28.5 \%$ & $32.6 \%$ & $3.3 \%$ & $100 \%$ \\
\hline & $\mathrm{A} / \mathrm{B}$ & $277.7 \%$ & $109.3 \%$ & $56.6 \%$ & $84.6 \%$ & - \\
\hline
\end{tabular}




\subsubsection{Use Internet service carefully}

Most medical schools in Japan are devoting attention to avoid Internet-related incidents in terms of privacy protection, which follows MCC. We must confirm the necessity of refraining from posting secret information to the Internet as well. Table 12 presents the result. They fundamentally understood that they should be unassertive to connect privacy and ICT. The question is that a "physician should not use blog or social network services without careful consideration, no matter how much they enjoy freedom of speech". We can find a significant increase in the number of students with a conservative attitude about internet service usage $(88.1 \mathrm{vs} 75.9 \%, \mathrm{p}<0.0001)$ after the workshop.

Table 12. Attitudes about Internet service usage.

\begin{tabular}{|c|c|c|c|c|c|c|}
\hline Year & Status & $\begin{array}{c}\text { Positive } \\
(5,4)\end{array}$ & $\begin{array}{c}\text { Average } \\
\text { (3) }\end{array}$ & $\begin{array}{c}\text { Negative } \\
(1,2)\end{array}$ & $\mathrm{N} / \mathrm{A}$ & Total \\
\hline \multirow{4}{*}{2011} & \multirow{2}{*}{ Before } & 95 & 19 & 9 & 0 & 123 \\
\hline & & $77.2 \%$ & $15 . \%$ & $7.3 \%$ & $0.0 \%$ & $100 \%$ \\
\hline & \multirow{2}{*}{ After } & 111 & 8 & 3 & 0 & 122 \\
\hline & & $91.0 \%$ & $6.6 \%$ & $2.5 \%$ & $0.0 \%$ & $100 \%$ \\
\hline \multirow{4}{*}{2012} & \multirow{2}{*}{ Before } & 81 & 17 & 23 & 13 & 134 \\
\hline & & $6.5 \%$ & $12.7 \%$ & $17.2 \%$ & $9.7 \%$ & $100 \%$ \\
\hline & \multirow{2}{*}{ After } & 107 & 13 & 3 & 9 & 132 \\
\hline & & $81.1 \%$ & $9.9 \%$ & $2.3 \%$ & $6.8 \%$ & $100 \%$ \\
\hline \multirow{4}{*}{2013} & \multirow{2}{*}{ Before } & 109 & 14 & 6 & 9 & 138 \\
\hline & & $79.0 \%$ & $10.1 \%$ & $4.4 \%$ & $6.5 \%$ & $100 \%$ \\
\hline & \multirow{2}{*}{ After } & 115 & 9 & 1 & 11 & 136 \\
\hline & & $84.6 \%$ & $6.6 \%$ & $0.7 \%$ & $8.1 \%$ & $100 \%$ \\
\hline \multirow{4}{*}{2014} & \multirow{2}{*}{ Before } & 113 & 12 & 8 & 4 & 137 \\
\hline & & $82.5 \%$ & $8.8 \%$ & $5.8 \%$ & $2.9 \%$ & $100 \%$ \\
\hline & \multirow{2}{*}{ After } & 122 & 9 & 4 & 1 & 136 \\
\hline & & $89.7 \%$ & $6.6 \%$ & $2.9 \%$ & $0.7 \%$ & $100 \%$ \\
\hline \multirow{4}{*}{2015} & \multirow{2}{*}{ Before } & 110 & 19 & 8 & 0 & 137 \\
\hline & & $80.3 \%$ & $14.0 \%$ & $5.8 \%$ & $0.0 \%$ & $100 \%$ \\
\hline & \multirow{2}{*}{ After } & 128 & 6 & 2 & 0 & 136 \\
\hline & & $94.1 \%$ & $4.4 \%$ & $1.5 \%$ & $0.0 \%$ & $100 \%$ \\
\hline \multirow{5}{*}{ TOTAL } & \multirow{2}{*}{ Before } & 508 & 81 & 54 & 26 & 669 \\
\hline & & $75.9 \%$ & $12.1 \%$ & $8.1 \%$ & $3.9 \%$ & $100 \%$ \\
\hline & \multirow{2}{*}{ After } & 583 & 45 & 13 & 21 & 662 \\
\hline & & $88.1 \%$ & $6.8 \%$ & $2.0 \%$ & $3.2 \%$ & $100 \%$ \\
\hline & $\mathrm{A} / \mathrm{B}$ & $114.8 \%$ & $55.6 \%$ & $24.1 \%$ & $80.8 \%$ & - \\
\hline
\end{tabular}




\subsubsection{Scenarios}

Table 13 presents the overall evaluation of scenarios by students. Since we had a full-day workshop in 2011 and 2012, they evaluated two scenarios. Therefore, the number of answers is doubled as compared with the number of participants. In most years, positive evaluation is much higher than negative one. Positive answers are remarkably high in full-day workshops. We can consider that repeated practice deepened understanding.

Table 13. Evaluation of scenario.

\begin{tabular}{|c|c|c|c|c|c|c|}
\hline Year & Status & $\begin{array}{c}\text { Positive } \\
(5,4)\end{array}$ & $\begin{array}{c}\text { Average } \\
\text { (3) }\end{array}$ & $\begin{array}{c}\text { Negative } \\
(1,2)\end{array}$ & $\mathrm{N} / \mathrm{A}$ & Total \\
\hline 2011 & After & $\begin{array}{r}201 \\
81.4 \%\end{array}$ & $\begin{array}{r}30 \\
12.2 \%\end{array}$ & $\begin{array}{r}16 \\
6.5 \%\end{array}$ & $\begin{array}{r}0 \\
0.0 \%\end{array}$ & $\begin{array}{r}247 \\
100 \%\end{array}$ \\
\hline 2012 & After & $\begin{array}{r}207 \\
81.2 \%\end{array}$ & $\begin{array}{r}30 \\
11.8 \%\end{array}$ & $\begin{array}{r}18 \\
7.1 \%\end{array}$ & $\begin{array}{r}0 \\
0.0 \%\end{array}$ & $\begin{array}{r}255 \\
100 \%\end{array}$ \\
\hline 2013 & After & $\begin{array}{r}88 \\
64.7 \%\end{array}$ & $\begin{array}{r}28 \\
20.6 \%\end{array}$ & $\begin{array}{r}16 \\
11.8 \%\end{array}$ & $\begin{array}{r}4 \\
2.9 \% \\
\end{array}$ & $\begin{array}{r}136 \\
100 \%\end{array}$ \\
\hline 2014 & After & $\begin{array}{r}100 \\
73.5 \%\end{array}$ & $\begin{array}{r}25 \\
18.4 \%\end{array}$ & $\begin{array}{r}11 \\
8.1 \%\end{array}$ & $\begin{array}{r}0 \\
0.0 \%\end{array}$ & $\begin{array}{r}136 \\
100 \%\end{array}$ \\
\hline 2015 & After & $\begin{array}{r}102 \\
74.5 \%\end{array}$ & $\begin{array}{r}28 \\
20.4 \%\end{array}$ & $\begin{array}{r}7 \\
5.1 \%\end{array}$ & $\begin{array}{r}0 \\
0.0 \%\end{array}$ & $\begin{array}{r}137 \\
100 \%\end{array}$ \\
\hline TOTAL & After & $\begin{array}{r}596 \\
73.5 \%\end{array}$ & $\begin{array}{r}113 \\
14.6 \%\end{array}$ & $\begin{array}{r}61 \\
8.3 \%\end{array}$ & $\begin{array}{r}4 \\
0.5 \%\end{array}$ & $\begin{array}{r}774 \\
100 \%\end{array}$ \\
\hline & $\%$ & $77.0 \%$ & $14.6 \%$ & $7.9 \%$ & $0.5 \%$ & $100 \%$ \\
\hline
\end{tabular}

\subsubsection{Facilitators' commission}

As we described in 2.8, we introduced student facilitators from other departments (mainly from school of law) to stimulate discussion, and to increase interdisciplinary interest. We asked for ideas on student facilitators from 2011 to 2014 as shown in Table 14. Since the workshop in 2011 and 2012 was full-day, students stayed with facilitators for a long time. There were many facilitators in 2011-2013 (9, 9, and 17, respectively) but the number decreased in 2014 (4). Facilitators were generally welcomed by students. Therefore, we can say that learning purpose No. 3 (2.4.3) was achieved.

Table 14. Evaluation of facilitator activity.

\begin{tabular}{|c|c|r|r|r|r|r|}
\hline \multirow{2}{*}{ Year } & Status & $\begin{array}{c}\text { Positive } \\
(5,4)\end{array}$ & $\begin{array}{c}\text { Average } \\
(3)\end{array}$ & $\begin{array}{r}\text { Negative } \\
(1,2)\end{array}$ & N/A & Total \\
\hline \multirow{2}{*}{2011} & \multirow{2}{*}{ After } & 193 & 30 & 22 & 0 & 245 \\
& & $78.8 \%$ & $12.2 \%$ & $9.0 \%$ & $0.0 \%$ & $100 \%$ \\
\hline \multirow{2}{*}{2012} & \multirow{2}{*}{ After } & 194 & 40 & 26 & 2 & 262 \\
& & $74 \%$ & $15.3 \%$ & $9.9 \%$ & $0.8 \%$ & $100 \%$ \\
\hline \multirow{2}{*}{2013} & After & 110 & 15 & 7 & 4 & 136 \\
& & $80.9 \%$ & $11.0 \%$ & $5.2 \%$ & $2.9 \%$ & $100 \%$ \\
\hline \multirow{2}{*}{2014} & After & $52.0 \%$ & $32.7 \%$ & 39 & 0 & 254 \\
& & 629 & 132 & $15.4 \%$ & $0.0 \%$ & $100 \%$ \\
\hline \multirow{2}{*}{ TOTAL } & After & $70.1 \%$ & $18.7 \%$ & $10.5 \%$ & $0.7 \%$ & 897 \\
& & & & & & $100 \%$ \\
\hline
\end{tabular}




\subsubsection{Total satisfaction for the workshop}

At the end, we asked about the overall satisfaction with this workshop. Table 15 presents the results. The frequency of positive answers was 74-94\%. We can say that the confidentiality workshop was well-planned and that it was highly appreciated by participants. Without a positive attitude and discussion, such result would never appear. Therefore, we can say that learning purpose No. 2 (2.4.2) was achieved.

Table 15. Overall satisfaction with confidentiality workshop.

\begin{tabular}{|c|c|c|c|c|c|c|}
\hline Year & Status & $\begin{array}{c}\text { Positive } \\
(5,4)\end{array}$ & $\begin{array}{l}\text { Average } \\
\text { (3) }\end{array}$ & $\begin{array}{c}\text { Negative } \\
(1,2)\end{array}$ & $\mathrm{N} / \mathrm{A}$ & Total \\
\hline \multirow{2}{*}{2011} & \multirow{2}{*}{ After } & 112 & 7 & 0 & 0 & 119 \\
\hline & & $94.1 \%$ & $5.9 \%$ & $0.0 \%$ & $0.0 \%$ & $100 \%$ \\
\hline \multirow{2}{*}{2012} & \multirow{2}{*}{ After } & 104 & 17 & 3 & 10 & 134 \\
\hline & & $77.6 \%$ & $12.7 \%$ & $2.2 \%$ & $7.5 \%$ & $100 \%$ \\
\hline \multirow{2}{*}{2013} & \multirow{2}{*}{ After } & 102 & 23 & 3 & 10 & 138 \\
\hline & & $73.9 \%$ & $16.7 \%$ & $2.2 \%$ & $7.3 \%$ & $100 \%$ \\
\hline \multirow{2}{*}{2014} & \multirow{2}{*}{ After } & 108 & 18 & 10 & 0 & 136 \\
\hline & & $79.4 \%$ & $13.2 \%$ & $7.4 \%$ & $0.0 \%$ & $100 \%$ \\
\hline \multirow{2}{*}{2015} & \multirow{2}{*}{ After } & 112 & 20 & 4 & 0 & 136 \\
\hline & & $82.4 \%$ & $14.7 \%$ & $2.9 \%$ & $0.0 \%$ & $100 . \%$ \\
\hline \multirow{2}{*}{ TOTAL } & \multirow{2}{*}{ After } & 538 & 85 & 20 & 20 & 663 \\
\hline & & $81.2 \%$ & $12.8 \%$ & $3.0 \%$ & $3.0 \%$ & $100 . \%$ \\
\hline
\end{tabular}

\subsection{Positive Commitment and Growth of Facilitator}

\subsubsection{Facilitators' contributions to improve the workshop}

Facilitators attend pre-workshops, main sessions, and review meeting. In each aspect, their fresh ideas worked well. Here are some examples of contributions to review meetings.

1) This scenario is much too complex, and much too swallow. We need to correct that at the next opportunity.

2) In the full-day session, we should participate like other students in the first cycle, and to start facilitation from the second round. In doing so, they remember us and feel easy about raising questions.

3) Conclusions in my committed team were that we would not make decisions, and instead ask for decisions by professionals. In this scenario, facilitation guidebook should be revised so as not to lead to such solutions.

\subsubsection{Afterwards}

In January 2017, we sent a letter to former facilitators to assess the effectiveness of this experience. Some comments are listed below.

\section{1) Mr. A. W. (Law, Currently law school student)}

I attended confidentiality workshops four times from their beginning. The largest benefit was that I was able to circulate the PDCA cycle in my mind to become a better facilitator. To understand the teacher's role as a staff member was also a valuable opportunity to grow my mindset. Furthermore, review meetings made it fun to increase interdisciplinary sense among facilitators. I am sure the experience will contribute to my career path as a lawyer.

\section{2) Ms. Y. I. (Law, Currently works as national government officer)}

The confidential workshop was my first moment to realize that I was treated as a legal professional. The workshop encouraged me to accept diverse ideas and people in a different discipline.

\section{3) Ms. R. Y. (Law, Currently works as a national government officer)}

Confidentiality as a public officer is required by law in my current workplace. Knowledge form the workshop is still alive in my mind.

\section{4) Ms. N. I. (Education, Currently works as a systems engineer)}

Learning the importance of interdisciplinary mobility was my largest benefit gained from this workshop. My business requires me to act flexibly. The experience contributed a lot. 


\section{5) Ms. E. C. (Education, Currently studying music in the U.S.A.)}

I still remember the workshop as an opportunity to meet future physicians, university teachers, facilitators coming from a legal background, and others. It was a difficult task for me to work in a multidisciplinary field. Now I am working abroad and confronting globalization and diversity daily. The experience still resonates with the origin of my career.

We can see that not only main workshops, but review meetings have an important role to tie and reconfirm many ideas and disciplines. It was an impressive experience for them. This is also important to maintain long-term amity between law facilitators and non-law facilitators. Therefore, we can consider that appointment of diverse facilitators is a great idea for the Confidentiality workshop. Moreover, we believe that interdisciplinary understanding is an important education, so that large universities should prepare such opportunities more frequently.

\section{Conclusion and Discussion}

\subsection{General Story}

At most universities around the globe, the importance of confidentiality is recognized, but its understanding and saturation level are doubtful. In Japan, medical education is standardized to let schools follow the MCC, but confidentiality is not a major topic. In contrast, our approach started from law, setting confidentiality as a core interest to maintain sustainability of safety in medical systems. Kameoka called for collaboration to Hamada and Kanaya. The workshop has continued for eight years, produced many innovative ideas such as scenario-based discussion, and outside facilitator's commission. These ideas were supported by most students and facilitators. Therefore, we conclude that our Confidentiality Workshop was successful. To the best of our knowledge, this was the first interdisciplinary educational program of law and medicine. To conclude this report, we should review important factors to make our future work more successful, and assess accompanying possible risks and limitations that might invite failure.

\subsection{Honest Effort to Realize Interdisciplinary Field}

One important factor to analyze the success of our project was that the teachers had immunity to accept interdisciplinary methods when they were undergraduate students, and had maintained that sense. Kameoka's roommate was a law student. He was strong at debate, and repeatedly told Kameoka "what we learn in the School of Law is not knowledge, but logic and rhetoric to respond immediately using a logical path and adequate words." Hamada and Kanaya share the same root. Although they passed entrance exams for the School of Law, they also become members of Pre-Seminar called "computer science." To understand together, and to compromise, law students and engineering students had quite a lot of discussion. Finally, we learned importance of interdisciplinary communication.

Therefore, we can say all teachers have become accustomed to developing interdisciplinary discussion. Additionally, they tried to study the field of each other without feeling complex together. We spent enormous amounts of time to study medicine and law to establish the Confidentiality Workshop, and had a lot of fun in the process.

\subsection{Regular Maintenance of Scenarios}

To compile a scenario, we devoted maximum attention to satisfying ourselves that the scenario was correct in terms of the legal interpretation, and also that it was correct as a medical story. However, we had to regularly update the scenario because both medicine and law evolved. For example, in 2009, we created the scenario of A/H1N1 influenza when the environment around this disorder changed violently. The population of patients had expanded (9 million), reporting duties necessary for physicians to local government by law were impossible to comply with. Therefore, the Ministry of Health, Labor and Welfare changed the category of A/H1N1 influenza by amendment of its ordinance to limit the administrative tasks. To trace such administrative movements and to reflect them in the scenario was not easy. Today, a cure for this disorder has been established, so there is not too much anxiety associated with it. Therefore, we replaced this scenario with another one. In this case, the progress of medicine overwhelmed our old scenario. A scenario creator had to devote maximum attention to the latest trends of law and medical science. Moreover, updating scenarios required elaborate collaborative work between legal specialists and physicians. Communication skills related to the discipline were important.

\subsection{Supply of New Facilitators}

The facilitators were also students. It is unavoidable to include a generation of circulation in the framework. However, it was quite difficult to find students who were interested in this topic. OME created many posters, but it was ineffective. Until 2013, Hamada had his project and lectured at Tohoku University, where it was easy to recruit talented students as facilitators. However, Hamada moved to Thailand in 2014. As an urgent issue, we must rebuild a new system to gather facilitators. 


\subsection{To Respect Legal Duties under the Core Curriculum}

As we described in chapter 1, medical education standards at Japanese universities are defined by guidelines: the Core Curriculum. We must remember, although confidentiality is a core value of sustainability of medical services, the core curriculum includes other legal, ethical, and compliance-related issues. We have no idea to deny the importance of personal information protection, but this story is an extension of existing ideas of privacy that have prevailed since the 19th century. To consider a balance between personal information protection and adequate usage of such information is a fundamentally different story as confidentiality, which has more than a 2,000 year history. If physicians do not maintain the privacy of patients, patients will refrain from telling the truth to physicians. Consequently, appropriate treatment will become impossible, which will lead to corruption of medical systems. The Core curriculum has just updated in 2016FY. We must raise our voices to include increasing demands for confidentiality.

\subsection{Limitation of the Study}

There are several limitations in the present study that we should mention. First, confidentiality is not the only subject that medical students have to learn regarding the legal aspects of medical practice. In our medical school, students learn medical ethics including medical research ethics mainly in the first and third years of their six-year undergraduate medical education. It might be helpful to include these other medico-legal issues in a future workshop.

Second, confidentiality alone is not enough to solve the social problems of patients, such as those in the case of child abuse demonstrated in our first scenario. Collaboration with a variety of professionals including social-welfare professionals is essential. In fact, our medical students intensively learn social welfare, including the roles of a variety of social-welfare professionals not only by listening to lectures but also by participating in medical practice training in wards and outpatient clinics.

Third, our confidentiality workshop may be more effective when it is provided later during the six-year medical education, such as in the 4th year. In our medical school, however, first year students visit wards and outpatient clinics in our university hospital and other medical facilities during the course named "early medical exposure". We believe, therefore, that having our first year students effectively learn the importance of confidentiality is essential.

Fourth, we were not able to evaluate the long-term effects of our confidentiality workshop. This is because our students learn medical ethics continuously for six years, rendering it difficult to distinguish the effects of this workshop from those of other educational courses related to confidentiality. However, we believe our confidentiality workshop for 1st-year students stands as a first step to learn one of their most important duties.

Finally, this kind of confidentiality workshop may not be feasible for every university, particularly for universities without a law department. We believe that teachers of a medical college or a university without a law department can still collaborate with law teachers of another university to plan an educational activity like our workshop.

\subsection{Confidentiality Workshop, Afterwards}

Hamada has already left; Kameoka has also left Tohoku University. Kagaya decided to continue this workshop by calling up Kameoka and Hamada on demand in 2017. This workshop is a unique fruit of interdisciplinary trials for eight years. We hope that our work described in this paper will contribute to readers like a star in the dark sky leading students to new interdisciplinary challenges.

\section{REFERENCES}

[1] Akabayashi, A., Inaba, K., and Nara, M., "Introduction to medical ethics," Keiso-shobo, 1: 171-190 (2005) (in Japanese).

[2] Beauchamp, T. L., and Childress, J. F., Principles of Biomedical Ethics, Oxford University Press, New York (1979).

[3] Hope, R. A., Medical Ethics: A Very Short Introduction, Oxford University Press, Oxford (2004).

[4] Jonsen, A. R., Siegler, M., and Winslade, W., Clinical Ethics, Macmillan, New York (1982).

[5] Rogers, W. A., and Draper, H., "Confidentiality and the ethics of medical ethics," Journal of Medical Ethics, 29(4): 220-224 (2003). doi:10.1136/jme.29.4.220

[6] Blightman, K., Griffiths, S., and Danbury, C., "Patient confidentiality: When can a breach be justified?" Continuing Education in Anaesthesia, Critical Care \& Pain, 14(2): 52-56 (2013). doi:10.1093/bjaceaccp/mkt032

[7] Agyapong, V. I. O., Kirrane, R., and Bangaru, R., "Medical confidentiality versus disclosure: Ethical and legal dilemmas," Journal of Forensic and Legal Medicine, 16: 93-96 (2016).

[8] Odunsi, B., "Should caregivers be compelled to disclose patients' HIV infection to the patients' sex partners without consent?" Studies in Family Planning, 38(4): 297-306 (2007). doi:10.1111/j.1728-4465.2007.00142.x

[9] Lo, B., Resolving Ethical Dilemmas: A Guide for Clinicians, Lippincott Williams \& Wilkins, Philadelphia (2015).

\section{Appendix: Scenarios Used in Confidentiality Workshops}

All scenarios (except Scenario 3, originally created by OME, are approved for other purposes, and for use in a Confidentiality workshop.) were drafted by Hamada and Kanaya and were confirmed by Kameoka. Scenarios 1 to 3 are basic cases, and 4 to 6 are advanced ones. In scenario 6, we tried to include daily topics that are familiar to students. All scenarios are fictions, no relation to any actual cases or hospitals. 


\section{Scenario No. 1 Suspected Child Abuse}

A four-year-old boy who had been injured after falling from a veranda in the middle of the night were transferred to the division of emergency medicine at M Hospital, where you work as an orthopedic physician. His injury was not severe. You treated the boy successfully. However, you found many marks on his stomach. His 37-year-old father seemed quite normal, and explained that the marks had been caused by sports training. Do you acknowledge his explanation and let the child go home?

\section{Scenario No. 2 Tuberculosis System Engineer Request}

A 30-year-old male patient (Mr. B) visited the division of internal medicine at M Hospital, in which you work as a physician. He had slight fever, chest pain and cough for a while until several days ago. According to him, he was fine at that time. However, you suspected tuberculosis and examined his sputum, which revealed that he was tuberculosis. You told him that you must report his case to the public healthcare center, but he entreated you, "I am doing a very important system development at work. If I leave now, it will affect quite a number of people. Please make an exception this time!" Do you accept his request and argument and let him go home?

\section{Scenario No. 3 HIV-Positive Boyfriend}

A 30-year-old male patient (Mr. C) accompanied by his fiancée (Ms. D) visited the division of internal medicine at M Hospital, in which you work as a physician. He complained of weakness, slight fever, and continuous cold-like symptoms after returning from a business trip to Southeast Asia. You recommended that he take an HIV-test. The result was positive. One day, Ms. D came to you alone, asking that you disclose the result to her. Do you tell the result to her?

\section{Scenario 4 Fiancée in Deep Depression}

You are a psychiatrist working for in the psychopathology division of M Hospital. You have been taking care of Ms. $G$, who is suffering from severe depression. Recently, she imagines death in whatever she sees. The possibility of admission is approaching. She does not have a good relationship with her mother, but she has a boyfriend to whom she is engaged. Making a new family with him is her last hope to live a happy life.

One day, Mr. H, your classmate from the School of Medicine told you that he is going to marry. He showed you a picture of his girlfriend. You were amazed to see that it was a picture of Ms. G. Mr. H seemed as though he knew nothing about her condition. What should you do?

\section{Scenario 5 Traffic Accident Offender}

You work as a physician at the division of emergency medicine of M Hospital. You are treating a male patient (Mr. E) who caused a head-on collision accident when his truck struck a car. He was badly injured in the accident. Mr. E's consciousness level is quite bad with acute bleeding. He said, "I was driving between Tokyo and Sendai three times within two days, 40 hours.... To fight against sleep, I was drinking whiskey at that moment.... I am guilty, and sorry for victims..." Ms. C, working as a nurse, understood his statement, too. The car hit by Mr. E's truck had four passengers. Presumably, all of them were killed. Mr. E was sent to the emergency operation room, but no one knows when or if he will return. Once you leave the treatment room, you are surrounded by police officers, rescue team members, TV crews, and a man who claims that he is a relative of the victims, all asking many questions about Mr. E. What do you feel an appropriate action at that time is?

\section{Scenario 6 Epilepsy Driver}

You are a neurologist in the neurology division of M Hospital. You have been taking care of Mr. H. He has been suffering repeatedly from sudden syncope and immobilization. You recommended that he undergo electroencephalography. The result was negative. Therefore you diagnosed him as having slight temporal epilepsy. By taking an antiepilepticum, the frequency of such fits would be decreased, but he still has syncope at times. As a physician, you repeatedly recommend that he refrain from driving. However, he cannot avoid driving a company car for business often. Do you continue treatment without taking action beyond recommending that he stops driving? If police officers asked you to explain his condition, would you disclose it?

\section{Scenario 6-2 Tsunami Rescue in Emergency Situation}

$M$ Hospital, where you work as a physician, sends a rescue team to X General Hospital located in a tsunamidevastated area. When you arrive, the hospital is crowded, with wounded patients groaning in pain, even in the corridor. Mr. J, a 49-year-old patient, lost his consciousness, with high fever. Apparently, he drank contaminated water, which caused severe pneumonia. We must send Mr. J to another hospital by helicopter immediately. We become surrounded by J's family members, police officers, rescue team members, TV crews, and are asked many questions about Mr. E. There is no time to confirm who is being truthful about their status, or not. Are you going to gather all people to explain his status using a megaphone? Is this activity permitted? 